\title{
The Effectiveness of Electronic Software in Developing English Language Skills for Eighth Grade Students in Wadi Al-Seer Directorate of Education/Jordan
}

\author{
Hamza Maharmah $^{1}$ \\ ${ }^{1}$ The World Islamic Sciences \& Education University, Jordan \\ Correspondence: Hamza Maharmah, The World Islamic Sciences \& Education University, Jordan.
}

Received: March 8, 2020

Accepted: May 1, 2020

Online Published: June 16, 2021

doi:10.5539/mas.v15n4p37

URL: https://doi.org/10.5539/mas.v15n4p37

\begin{abstract}
The purpose of the study is to investigate the effect of using electronic software in the development the English language skills among students at primary stage, the researcher used a semi-experimental approach, and he chose an intentional sample, which consisted of (100) eighth grade students from Marj Al-Hamam Elementary School in the Directorate of Education in Wadi Al-Seer in Amman during the first semester of 2019/2020. The study sample was randomly distributed into two groups: the experimental and control with (50) students in each. The study tool was prepared, which is an achievement test (before and after me) and their validity and reliability were verified. The results showed that there were statistically significant differences at the level $(\mathrm{a}=0.05)$ between the mean scores of the control group and the experimental group, in favor of the experimental group in the post-test first studied using the electronic software. The study showed that there is an effect of electronic software in the development of English language skills. In light of the results, the researcher recommended the use of electronic software in schools.
\end{abstract}

Keywords: effectiveness, electronic software, development, English language skills, the basic stage in Jordan

\section{Introduction}

In light of the technological development that accompanies us in this era, the use of computers in education has become an indispensable necessity, and the teacher's job has departed from its traditional role of indoctrination, and has new jobs that require new experiences in preparing. In order to keep pace with technological development, and thus it can be said: The teacher of the twenty-first century must be academic, educational and technologically advanced (Al-Heila, 2000). This interest came as a result of several factors, including the inability of the traditional education system to prepare students who are able to keep pace with the rapid developments around them, and who are able to become productive elements in their societies.

Computerized educational programs are one of the innovations in this technology, and they go back to the ideas of the behaviorist (Skinner) in the mid-fifties, and what it presented with regard to programmed education. With the development of computers since then, the sector of computer programs in general and computerized educational programs in particular has witnessed remarkable development and progress, as many technologies have been integrated into these programs, such as artificial intelligence, expert systems, and databases. This resulted in many types of these programs, which will be discussed later.

These computerized educational programs have proven effective in different educational situations, and by reviewing many of the literature, the advantages of educational computer programs in the learning process have been classified, according to the elements of the Gagne strategy, which should be carried out by the teacher or the computer program, and these elements are: Orientation, presentation, practice, testing, retention and transmission (Abu Khatwa and Abdel-Aty, 2009).

Hence, we are in dire need of special methods through which we teach the development of effective thinking skills among learners at an early age, and thus help them to learn, and from the educators' perspective, the computerized educational programs are effective, as they help the child to think and learn in a better way (Al-Heilah and Ghanem, 2002). 
Language is one of the basic sciences that should be given utmost importance in the early stages of education, as it is one of the most important links between humankind, and it is the natural product of the outcomes of human interaction, such as sciences, literature, thought, beliefs, customs, traditions, and economic, political, and social aspects. Since ancient times, it is a civilized human phenomenon; because it is a means of understanding between people, a thinking machine, and a means of transferring ideas (Ghoneim, 2002).

Hence, it is necessary to follow modern and new methods to motivate students, and it is necessary to develop positive attitudes towards learning to read and write correctly, and develop their basic skills among students. Modern educational methods focus on the use of high-level educational technology, and contribute to making changes in students' knowledge, and this was demonstrated by using computerized educational programs of all kinds (Huppert, Yaakobi, \& Lezarovvitz, 2001), to apply computerized educational programs in education.

\subsection{The Study Problem}

The researcher noted the students' low level of English language skills, and many previous studies confirmed the low diversity in the use of modern teaching strategies in teaching English, which is reflected in the low level of English language skills among students.

After interviewing some teachers, the researcher found that teachers still use old methods, and lead to unaccepted results for the educational process in the basic stage in both public and private schools, which is a level below what is required in light of the attempt to adapt with the developments of the times, its requirements and challenges.

From this point of view, the researcher tried to enhance the use of technology in general in teaching, and help teachers design their own electronic software to raise the level of students in the four language skills.

\subsection{The Questions of the Study}

The researcher seeks to answer the following questions:

1) Is there an effect of electronic software in the development of reading skill of the English language?

2) Is there an effect of electronic software in the development of listening skill of the English language?

3) Is there an effect of electronic software in the development of speaking skill of the English language?

4) Is there an effect of electronic software in the development of writing skill of the English language?

\subsection{Definition of Terms}

Effectiveness: The impact that the electronic software will have on developing English language skills such as reading, listening, speaking and writing for eighth grade students in the city of Amman.

Electronic Software: Multimedia software that a team of specialists designed, developed, implemented and uploaded on a website to develop reading, listening, speaking and writing skills in the English language.

Skill: Outstanding performance and mastery of the four English language skills of reading, listening, speaking and writing by eighth-grade students after studying the course via electronic software.

\section{Previous Studies}

Al-Niyadi (2009) study showed that there was no significant difference in the performance of the study sample members on the pre-test (in Arabic grammar) and according to the group variable (experimental and control), while there were statistically significant differences at the level of statistical significance $(\alpha=05.0)$. (On the achievement of fourth grade students and the effect of using educational software on the performance of the study sample members on the posttest and according to the group variable (experimental and control), and in favor of the performance of the experimental group students on the post test, and there is a statistically significant difference at the level of statistical significance $(\alpha=05.0)$ In the performance of the experimental group students and according to the test variable (pre and post), and in favor of the performance of the experimental group students on the post test.

Zalaei (2008) study showed no significant differences between the average achievement of students in the experimental group and the average achievement of students in the control group due to the use of a computer program to learn English grammar in favor of the experimental group at the level of remembering. It also showed There are statistically significant differences between the average achievement of students in the experimental group and the average achievement of students in the control group in favor of the experimental group at the level of understanding, in addition to the presence of statistically significant differences between the 
average achievement of students in both groups in the overall test dimensional in favor of the experimental group.

A study of Jabr (2007) showed no significant differences at the significance level $(\alpha=05.0)$ in students' achievement in mathematics due to the teaching method (computer, traditional) and in favor of computer teaching. The study did not reveal any statistically significant differences due to gender or there are positive attitudes among mathematics teachers towards the use of computers as an educational tool in teaching mathematics.

Al-Harash et al. (2006) study showed no significant differences in the effect of using two different educational softwares on the achievement of first-grade students in mathematics and in favor of the group that learned in the style of computerized educational games.

Al-Dail (2005) study indicated that there were statistically significant differences in the direct (immediate) and delayed (retention) achievement of the study sample members in the three arithmetic skills (addition, subtraction, and multiplication) due to the use of the computer-based learning strategy.

Obaidat (2005) study showed no significant differences in students' achievement of some mathematical concepts on the direct and delayed test due to the use of computerized educational games and in favor of the experimental group that learned some mathematical concepts through computerized educational games, while the results showed that there were no significant differences. Statistical significance in the direct and delayed achievement of the experimental group members, attributable to gender.

Douidi (2003) study indicated that there were no statistically significant differences at the significance level $(\alpha=$ 05.0) in the achievement of the three groups in the reading and writing course due to the use of computer games and educational programs when there were statistically significant differences between the results. Significance level $(\alpha=05.0)$ in the growth of each creative thinking ability separately (fluency, flexibility, originality, and details) as well as in the development of creative thinking ability as a whole for the benefit of the first experimental group who used educational computer games.

Al-Heila and Ghoneim (2002) study revealed no significant differences at the level of significance $(\alpha=05.0)$ between the mean scores of the study groups' students on the direct and delayed achievement test due to the teaching method, and in favor of the students who were treated with computerized language games first. Then in favor of the students who were treated with linguistic educational games secondly, and then in favor of the students who were treated in the usual way, as the results showed significant differences between the average scores of the students of the study groups on the direct and delayed achievement test due to gender. Students and for the benefit of women.

\section{The Study Methodology}

\subsection{Population of the Study}

The population of the study consisted of all eighth-grade students in private schools in the capital Amman in $2019 / 2020$.

\subsection{The Sample of the Study}

The sample comprised (100) male and female students from the eighth grade of the basic stage in the Marj Al-Hamam Basic School in the Wadi Al-Seer Directorate of Education. The members were chosen intentionally because there are three classes for the eighth grade, they were randomly distributed into two divisions, control and experimental with (50) students in each. Table 1 shows the study sample.

Table 1 . The study sample distribution

\begin{tabular}{llll}
\hline Group & Gender & N. & Total \\
\hline Experimental & Male & 30 & 50 \\
\multirow{3}{*}{ Control } & Female & 20 & \\
& Male & 28 & 50 \\
& Female & 22 &
\end{tabular}

The researcher used T-test to verify that the two groups are equivalent. Table 2 shows the results of the analysis: 
Table 2. Equalization of the control and experimental groups before applying the tool

\begin{tabular}{llllll}
\hline Group & N. & Mean & STD & T value & Sig \\
\hline Experimental & 50 & 18.89 & 5.69 & 1.149 & 0.258 \\
Control & 50 & 20.73 & 5.67 & & \\
\hline
\end{tabular}

Table 2 showed that the value of T (1.149) at the significance level (0.258) which is statistically significant, this shows the equality of the two groups before the application of the study.

\section{Design an electronic software to develop English language skills:}

The researcher dealt with educational design models in the previous chapter and concluded that the educational design model includes a systematic method consisting of a set of arranged procedures to plan and develop the best educational methods to achieve the desired learning goals according to specific conditions that include the development of educational aids, identification and evaluation of all learning activities.

\subsection{The Study Tool}

In this study, a tool was used to achieve the goal of the study, which is: an achievement test in English language skills for the eighth grade, and the following are the steps for designing and building the study tool.

\section{Achievement test for the four skills of English language}

In view of the nature of the study in terms of its purpose, methodology, and society, the researcher prepared an achievement test in the skills of the fourth unit of the English language for the eighth grade. The study tool went through several steps until it became applicable, before and after, on the control and experimental groups, as follows:

- The first step: Determine the goal of the study tool: The goal of the study tool was to evaluate the effectiveness of a proposed electronic software in developing the English language skills of primary school students in Jordan.

- The second step: Analyzing the content of the fourth unit of the English language for the eighth grade, and determining the objectives associated with the content.

- The third step: Determining the type of the test and its vocabulary, where the questions varied between essay questions using the specification table during its preparation, and supplementation questions taking into account that the blank represents an important aspect and not a trivial aspect, and multiple choice questions so that the question poses a new situation and shows the wrong alternatives as if True and true and false questions, taking into account the use of phrases that are either true or false, whose validity is beyond doubt, and avoiding the use of long and complex sentences.

- The fourth step: Building a table of specifications for English language skills' achievement test in light of the of Bloom's cognitive levels. And building a table of specifications for the distribution of grades for the achievement test in the light of English language skills.

\subsubsection{The validity of the Study Tool}

Validity means that the test measures what it was designed to measure, the more you measure the goal for which it is designed, the greater will be the validity of the tool (Abdul-Raouf and Al-Masri, 2017).

\subsubsection{The Validity of the Test}

The researcher validated the test in two ways:

\section{Face Validity}

The researcher presented the test to 36 arbitrators with specialization in the field of curricula and teaching methods, and to educational supervisors to express their opinion on:
a. The appropriateness and clarity of the linguistic formulation of the test items.
b. The suitability of the test for the purpose for which it was designed.
c. The suitability of the paragraphs to the intended objective.
d. Judging the level of achievement measured by each of the test items.
e. The article considers individual differences.
f. Vocabulary is appropriate for the levels you measure. 
In light of the opinions of the arbitrators during their rest times, the test was put into its final form, where the researchers made some simple modifications. Among the modifications referred to by the arbitrators are the following:

a. Linguistic reformulation of the fourth question of the listening skill.

b. Determine the test time.

\section{Construct Validity}

The researcher applied the achievement test to a pilot study of eighth-grade students from outside the study sample, which numbered (50) male and female students, after adjusting the timetable for the English language, presentation of the fourth unit teaching, from the subject of the English language for the sixth grade of the primary section of the exploratory division in the usual way. And that to check the following: Determine the time for testing English language skills, as the appropriate time was one hour. The difficulty and discrimination coefficients were calculated. The test papers were corrected and the difficulty and discrimination coefficients were calculated for the 42 English language skills test questions distributed on reading, listening, speaking and writing skills.

\section{The reliability of the achievement test:}

The reliability of the test means the accuracy and consistency of the scale, i.e. that the test gives the same results or results close to them if it is re-applied to the same sample and in the same conditions and after a specified period of time. Therefore, the test stability was calculated as follows:

- Using the application and re-application method: (Test-Retest) the English language skills test was applied to an exploratory sample of the study community from outside the study sample, consisting of (50) male and female students, where the test was re-applied two weeks after the first application. By applying the correlation equation for (Pearson) scores, it was found that it is equal to (8.06) between the pre- and post-applications. It is noted from the results of the analysis that there is a significant positive correlation between the scores of the first two applications, the second is an achievement test, and that the test has high stability, and this confirms the accuracy of the study tool and its suitability for application to the actual sample members of the study. Thus, the achievement test for English language skills came out in its final form after ensuring its validity and stability, consisting of (42) questions.

- Internal consistency method (Cronbach alpha): The stability coefficients of the achievement test arbitration tool in the English language were calculated using the internal consistency method according to the Cronbach Alpha equation. Between (0.87-0.90) for the total reliability of the assessment tool for the achievement test in English language skills (0.90), and these stability coefficients are suitable for the purposes of the current study.

- Correction reliability: Another corrector corrected the test.

\subsection{Study Procedures}

The researcher followed the following procedures to achieve the goal of the study:

- Review the literature and previous studies related to the subject of the study.

- The researcher built the study tools and extracted the psychometric properties of them by applying them to an exploratory sample.

- The eighth grade, Division (B) from Marj Al-Hamam Elementary School was chosen as an experimental group, and Division (A) as a control group.

- The researcher and the English language teacher applied the achievement test to the students of the experimental and control groups as a pre-application.

- The third unit of the English language book for the eighth grade was taught to the students of the experimental group using electronic software, while the same unit was taught in the usual way for the students of the control group, and the application lasted for (4) weeks, the researcher followed up the work of the English language teacher participating in the experiment, and an agreement was reached with.

- The teacher provides the general and detailed objectives of the electronic software, and how to implement these objectives by using it.

- Preparing a posttest to develop English language skills (reading, listening, speaking and writing). 
- Ensure the validity and reliability of the study tools.

- After completing the teaching of the unit, the researcher applied the achievement test in the English language to the students of the experimental and control groups as a post-application.

- The teacher corrected the test and recorded the students' mark in the correction form, while the researcher organized the data and submitted it to the statistical program (SPSS), analyzed it statistically, interpreted the results and made recommendations.

- Presenting the results of the study in accurate tables according to the rules.

- Draw conclusions, discuss them, and suggest recommendations.

\subsection{Statistical Treatment}

The researcher used some appropriate statistical methods:

- The t-test which includes calculating the arithmetic means (mean), standard deviation, the difference between the means, T-value, significance level and effect size to verify the equivalence of the two groups (experimental and control) and to identify the extent to which English language skills are developed towards software.

- Pearson Correlation Coefficient (to calculate structural validity for the achievement test between the total score for skill and the total score for the achievement test.

- Cronbach's alpha equation and the split-half and Spearman method to measure the stability of the two study tools.

- Difficulty and discrimination coefficient for achievement test items.

- Analysis of Covariance, which is called in short (ANCOVA), and the aim of this analysis is to try to reduce the error of variance because the dependent variable (English language skills) has four levels.

\section{The Study Results}

The results were classified according to the study questions as follows:

\section{First: Results related to the effect of electronic software in the development of the skill of the English language?}

In order to test this question, the arithmetic averages and standard deviations of the scores of the study sample were calculated in the experimental group (which was subjected to the use of electronic software in teaching) and the control group (which was subjected to the usual method) in English language skills. Table 3 illustrates the results.

Table 3. Means and standard deviations of the scores of the two groups in the English language skills test

\begin{tabular}{lllll}
\hline Group & Number & Descriptive statistics & Pretest & Posttest \\
\hline Control & 50 & Mean & 20.73 & 28.05 \\
& & Standard deviation & 5.67 & 4.08 \\
Experimental & \multirow{2}{*}{50} & Mean & 18.89 & 33.89 \\
& & Standard deviation & 5.69 & 4.69 \\
Total & \multirow{2}{*}{100} & Mean & 19.81 & 30.97 \\
& & Standard deviation & 5.70 & 5.25
\end{tabular}

Table 3 shows apparent differences between the mean scores of the study sample for the two groups, and in the pre and posttests, where the mean in the pretest for the control group was (20.73) out of (40) scores, with standard deviation (5.67). The mean in the pre-test for the experimental group was (18.89) out of (40) scores, with a standard deviation of (5.69), that is, there is an apparent difference in the arithmetic mean between the two groups of (1.85) in favor of the control group. The results also indicate that the arithmetic mean in the post-test for the control group was (28.05) out of (40) scores, with standard deviation) 4.08), the arithmetic mean in the post-test for the experimental group was (33.89) out of (40) scores, with a standard deviation (4.69), that is, there is an apparent difference in the arithmetic mean between the two groups of (5.85) in favor of the experimental group.

The analysis of covariance (ANCOVA) was used to show the difference in the mean of the two groups. The results were as in the table 4 . 
Table 4. An analysis of covariance (ANCOVA) for the scores of the members of the two groups in the English language skills test

\begin{tabular}{llllllll}
\hline Source of variance & Sum of squares & $\mathrm{df}$ & Mean of squares & Calculated F & Sig & $\eta 2$ & Impact size \\
\hline Pretest & 742.946 & 1 & 742.946 & 195.453 & 0.000 & & \\
Teaching method & 616.164 & 1 & 616.164 & 162.099 & 0.000 & 0.776 & High \\
ERROR & 178.656 & 48 & 3.802 & & & & \\
Total & 49274.000 & 50 & & & & & \\
\hline
\end{tabular}

The results in Table 4 showed a significant difference between the mean scores of the members of the two groups, where the value of (calculated F) reached (162.099), and this value is statistically significant, which means rejecting the null hypothesis which states that "there is no significant difference between the mean scores of the two groups in the English language skills due to the use of electronic software in teaching.

Second: The results related to the answer to the first question and its contents: Is there an effect of electronic software in the development of reading skill of the English language?

In order to test this question, the arithmetic averages and standard deviations of the scores of the members in both groups in reading skill were calculated from the English language subject, and the results were as in table 5 below

Table 5. The arithmetic averages and standard deviations of the scores of the experimental and control groups in the reading skill in the English language test

\begin{tabular}{lllll}
\hline Group & Number & Descriptive statistics & Pretest & Posttest \\
\hline Control & 50 & Mean & 4.05 & 6.97 \\
& & Standard deviation & 2.35 & 1.38 \\
Experimental & \multirow{2}{*}{50} & Mean & 3.97 & 8.57 \\
& & Standard deviation & 1.75 & 1.40 \\
Total & \multirow{2}{*}{100} & Mean & 4.01 & 7.77 \\
& & Standard deviation & 2.05 & 1.61
\end{tabular}

Table 5 shows apparent differences between the mean scores of the members in both groups in the reading skill, and in the pre and posttests, where the results indicate that the arithmetic mean in the pre-test for the control group was (4.05), with a standard deviation (2.35), the arithmetic mean in the pre-test for the experimental group was (3.97), with a standard deviation (1.75), that is, there is an apparent difference in the arithmetic mean between the two groups (0.09) in favor of the control group. The results also indicate that the arithmetic mean in the reading skill in the post-test of the control group was (6.97), with standard deviation (1.38), while the arithmetic mean in the post-test for the experimental group was (8.57), with a standard deviation (1.40), that is, there is an apparent difference in the arithmetic mean in the reading skill between the two groups of (1.61) in favor of the experimental group.

Third: Results related to the answer to the second question and its contents: Is there an effect of electronic software in the development of listening skill of the English language?

In order to test this question, the arithmetic means and standard deviations of the scores of the members in both groups in listening skill were calculated from the English language subject and the results were as in Table 6 .

Table 6. Arithmetic averages and standard deviations of the scores of the experimental and control groups in the listening skill

\begin{tabular}{lllll}
\hline Group & Number & Descriptive statistics & Pretest & Posttest \\
\hline Control & 50 & Mean & 5.37 & 7.33 \\
& & Standard deviation & 2.17 & 1,12 \\
Experimental & \multirow{2}{*}{50} & Mean & 4.57 & 8.61 \\
& & Standard deviation & 1.93 & 1.13 \\
\multirow{2}{*}{ Total } & \multirow{2}{*}{100} & Mean & 4.97 & 7.97 \\
& & Standard deviation & 2.07 & 1.29 \\
\hline
\end{tabular}


Table 6 shows apparent differences between the mean scores of the members in both groups in listening skill, and in the pre and posttests, where the results indicate that the arithmetic mean in the pre-test for the control group was (5.37), with a standard deviation (2.17), while the arithmetic mean in the pre-test for the experimental group was (4.57), with a standard deviation of (1.93), that is, there is an apparent difference in the arithmetic mean between the two groups of $(0.81)$ in favor of the control group. The results also indicate that the arithmetic mean of listening skill in the post-test of the control group was (7.33), with a standard deviation (1.12), the arithmetic mean in the post-test for the experimental group was (8.61), with a standard deviation (1.13), that is, there is an apparent difference in the arithmetic mean in the listening skill between the two groups of an amount (1.29) for the experimental group.

Fourth: Results related to the answer to the third study question, the text of which is: Is there an effect of electronic software in the development of speaking skill of the English language?

In order to test this question, the arithmetic averages and standard deviations of the scores of the members of both groups were calculated in the speaking skill of the English language subject and the results are illustrated in Table 7.

Table 7. Arithmetic averages and standard deviations of the scores of individuals of the two experimental and control groups in speaking skill

\begin{tabular}{lllll}
\hline Group & Number & Descriptive statistics & Pretest & Posttest \\
\hline Control & 50 & Mean & 5.97 & 7.21 \\
& & Standard deviation & 1.58 & 1.45 \\
Experimental & \multirow{2}{*}{50} & Mean & 5.65 & 8.81 \\
& & Standard deviation & 1.36 & 1.62 \\
Total & \multirow{2}{*}{100} & Mean & 5.81 & 8.01 \\
& & Standard deviation & 1.47 & 1.72
\end{tabular}

Table 7 shows apparent differences between the mean scores of the members in both groups in speaking skill, and in the pre and posttests, where the results indicate that the arithmetic mean in the pre-test for the control group was (5.97), with a standard deviation (1.58), the arithmetic mean in the pre-test for the experimental group was (5.65), with a standard deviation (5.65), with a standard deviation (1.36), that is, there is an apparent difference in the arithmetic mean between the two groups of (0.33) in favor of the control group.

The results also indicate that the arithmetic mean of speaking skill in the post-test of the control group was (7.21), with a standard deviation of (1.45), the arithmetic mean in the post-test for the experimental group was (8.81), with a standard deviation (1.62), that is, there is an apparent difference in the arithmetic mean in the speaking skill between the two groups of (1.61) in favor of the experimental group.

Fifth: Results related to the answer to the four-study question: Is there an effect of electronic software in the development of writing skill of the English language?

In order to test this question, means and standard deviations of the scores of the members in both groups were calculated in the writing skill of the English language subject and the results were as in the table 8 .

Table 8. Arithmetic averages and standard deviations of the scores of individuals of the control and experimental groups in the writing skill in the English language test

\begin{tabular}{lllll}
\hline Group & Number & Descriptive statistics & Pretest & Posttest \\
\hline Control & 50 & Mean & 5.37 & 6.57 \\
& & Standard deviation & 1.76 & 1.24 \\
Experimental & \multirow{2}{*}{50} & Mean & 4.73 & 7.93 \\
& & Standard deviation & 1.55 & 1.45 \\
Total & \multirow{2}{*}{100} & Mean & 5.05 & 7.25 \\
& & Standard deviation & 1.68 & 1.50 \\
\hline
\end{tabular}


Table 8 shows that there are apparent differences between the mean scores of the study sample for the control and experimental groups in writing skill, and in the pre and posttests, where the results indicate that the arithmetic mean in the pre-test for the control group was (5.37), with a standard deviation (1.76), the arithmetic mean in the pre-test for the experimental group was (4.73), with a standard deviation (1.55), that is, there is an apparent difference in the arithmetic mean between the two groups of (0.65), in favor of the control group.

The results also indicate that the arithmetic mean in the writing skill in the post-test of the control group was (6.57), with a standard deviation (1.24), the arithmetic mean in the post-test for the experimental group was (7.93), with a standard deviation (1.45), that is, there is an apparent difference in the arithmetic mean in writing skill between the two groups of (1.37) in favor of the experimental group.

\subsection{Recommendations}

The researcher suggested some recommendations

1) Interest in teaching the four English language skills (reading, listening, speaking and writing) to students of the primary stage using electronic software, because of its impact on students' hearts and their motivation to learn.

2) Directing English language teachers to use educational software within the training and qualification programs provided to them.

3) The use of modern methods and strategies in education, such as the use of educational software.

4) Moving away from memorization and indoctrination in teaching in general and in developing the four English language skills (reading, listening, speaking and writing) in particular.

5) Focusing on the role of software in learning English for primary school students due to its effectiveness in the educational process.

\subsection{Study Suggestions}

1) Conducting more similar studies for all school levels in schools to find out the effectiveness of educational software in learning language skills.

2) Holding rehabilitative and training courses for the teaching staff at various teaching levels to keep pace with learning in the current era.

3) Encouraging the teaching staff in schools to use educational software and applying this to include all academic subjects.

4) Study the current situation in schools in general and know the reasons for the obstacles to the application of such software.

5) Conducting other studies similar to the current study that encourage learning using electronic software to develop other skills such as reading comprehension skills, critical reading, presentation skills, and writing skill

6) Benefiting from Arab and international experiences that have applied educational software to school curricula.

7) Develop educational strategic plans to advance the educational process for the better, according to operational plans and studied programs.

\section{References}

Abu Khatwa, A. (2009). Digital E-Learning Theory - Design - Production (1st ed.). House of the New University for Publishing, Alexandria, Egypt.

Al Neyadi, S. (2009). The effect of educational software on the achievement of fourth-grade students in Arabic grammar in Al Ain region. United Arab Emirates. Retrieved from https://www.edutrapedia.illaf.net/arabic/show_article.thtml?id=295

Al-Dayl, Saad Abdel-Rahman. (2005). The Effect of Computer Use in Teaching Mathematics on the Achievement of Second Grade Students. Journal of Educational and Psychological Sciences, 3, 46-61. University of Bahrain, Kingdom of Bahrain. 
Al-Harash, Ayed Hamdan, Ababneh, Ziyad, Walid Muhammad, \& Al-Dala'a, Osama "Mohammed Amin" Ahmed. (2006). The effect of using two different educational software on the achievement of first-grade students in mathematics. Tishreen University Journal for Studies and Research_Arts Series, 28(1). Humanities and Sciences

Al-Heilah, M. (2000). Educational Technology between Theory and Application (2nd floor). Dar Al Masirah for Publishing, Distribution and Printing, Amman, Jordan.

Al-Heilah, M., \& Ghoneim, A. (2002). The effect of computerized and ordinary language educational games in addressing reading difficulties among fourth grade students. An-Najah University Journal for Research, 16(2), 590-626. An-Najah National University.

Douidi, A. (2003). The effect of using computer games and educational programs on achievement and growth of creative thinking among first-grade students in the reading and writing course in Madinah. The Arabic Resala Journal, 22. King Abdulaziz University, Madinah.

Gaber, Waheeb, \& Wajih Gabr. (2007). The impact of computer use on seventh grade students' achievement in mathematics and their teachers' attitudes towards using it as an educational tool. Unpublished Master's Thesis. College of Graduate Studies, An-Najah National University, Nablus, Palestine.

Ghoneim, A. (2002). Linguistic educational games and their impact on addressing reading and writing difficulties for fourth-grade students in Jordan. Unpublished master's thesis, El Fasher University, Sudan.

Huppert, J., Yaakobi, J., \& Lezarovvitz, R. (2001). Learning Microbiology with Computer Simulations: Students' Academic Achievement by Method and Gender. Research in Science and Technological Education, 16(2), 231-246. https://doi.org/10.1080/0263514980160210

Obeidat, L. (2005). The effect of computerized educational games on the achievement of some mathematical concepts for third grade students in the first Irbid district. Unpublished master's thesis, The Hashemite University, Zarqa, Jordan.

Zulai'i, R. (2008). The effect of using a computer program on learning English grammar for first-year secondary school students in Jeddah. An unpublished master's thesis, Umm Al-Qura University, Makkah Al-Mukarramah, Saudi Arabia.

\section{Copyrights}

Copyright for this article is retained by the author(s), with first publication rights granted to the journal.

This is an open-access article distributed under the terms and conditions of the Creative Commons Attribution license (http://creativecommons.org/licenses/by/4.0/). 